\title{
ANALISIS MODEL KEGAGALAN RUMAH 2 LANTAI AKIBAT NEGATIVE SKIN FRICTION DAN CURAH HUJAN YANG TINGGI
}

\author{
Jeanfrie Chandra', Chaidir Anwar Makarim² \\ ${ }^{1}$ Program Studi Sarjana Teknik Sipil, Universitas Tarumanagara, Jl. Letjen S. Parman No.1 Jakarta \\ Jeanfrie.325170070@stu.untar.ac.id \\ ${ }^{2}$ Program Studi Sarjana Teknik Sipil, Universitas Tarumanagara, Jl. Letjen S. Parman No.1 Jakarta \\ chaidir259@gmail.com
}

Masuk: 19-08-2021, revisi: 19-08-2021, diterima untuk diterbitkan: 19-08-2021

\begin{abstract}
One of the problems that appear in a project is the presence of soft soil. In projects with soft soil types, it is necessary to manage the soil to increase the bearing capacity of soil. Soil subsidence on soft soil causes friction between the soil and the pile blanket, called the negative skin friction. Negative skin friction should not be neglected because it exerts a large enough force on the load that the pile must support. In addition, in designing an engineer must also pay attention to the optimal rainfall that will occur during the construction of a project and after that has an impact on the quality of the soil and foundation used. The topography of a project also needs to be considered, building a house on the edge of a slope can cause problems with slope instability. Increasing the load on the edge of the slope can reduce the safety factor of a slope. In this study, a modeling analysis will be carried out on a 2-story residential building that causes the house to collapse due to failure of the foundation design, the existence of negative frictional resistance on soft soil, and slope stability.
\end{abstract}

Keywords: bearing capacity; negative skin friction; slope stability

\section{ABSTRAK}

Salah satu permasalahan yang muncul pada suatu proyek adalah adanya tanah lunak. Pada proyek dengan jenis tanah lunak, perlu dilakukan perbaikan tanah untuk meningkatkan daya dukung tanah. Penurunan tanah pada tanah lunak menyebabkan gesekan antara tanah denan selimut tiang yang disebut fenomena tahanan friksi negatif. Tahanan friksi negatif tidak boleh diabaikan karena memberikan gaya yang cukup besar terhadap beban yang harus ditopang oleh tiang. Oleh karena itu, seorang insinyur harus memperhatikan dan mengetahui mengenai perilaku tanah lunak. Selain itu dalam mendesain, seorang insinyur juga harus memperhatikan mengenai curah hujan optimal yang akan terjadi selama pengerjaan suatu proyek dan setelahnya yang berdampak pada kualitas tanah dan fondasi yang digunakan. Topografi suatu proyek juga perlu diperhatikan, membangun rumah di tepi lereng dapat menyebabkan permasalahan pada ketidakstabilan lereng. Menambah beban pada tepi lereng dapat mengurangi faktor keamanan suatu lereng. Pada penelitian kali ini, akan dilakukan analisis permodelan pada suatu bangunan rumah tinggal 2 lantai yang menyebabkan rumah tersebut runtuh akibat kegagalan desain fondasi, adanya tahanan friksi negatif pada tanah lunak dan ketidakstabilan lereng.

Kata kunci: daya dukung tiang pancang; tahanan friksi negatif; ketidakstabilan lereng

\section{PENDAHULUAN}

Pertumbuhan penduduk yang terus meningkat menyebabkan dampak besar bagi kehidupan masyarakat. Pertambahan penduduk inilah yang menuntut bertambahnya kebutuhan lahan tinggal. Kekuatan sebuah tidak lepas dari kekuatan fondasi sebagai stuktur bawahnya. Penggunaan dan pemilihan fondasi disesuaikan dengan jenis tanah pada lokasi rumah tersebut. Salah satu masalah yang seringkali muncul pada suatu proyek adalah adanya tanah lunak. Dalam pembangunan suatu proyek dengan jenis tanah lunak, maka tanah tersebut harus dilakukan perbaikan. Seorang insinyur harus mengetahui dan mengenal karakteristik mengenai tanah lunak. Tanah lunak mempunyai daya dukung yang lemah. Tanah lunak juga menimbulkan beberapa masalah. Salah satu masalah yang terjadi pada tanah lunak adalah negative skin friction. Negative skin friction adalah gesekan negatif antara tanah dengan selimut tiang yang menambah beban untuk ditopang oleh tiang. Ini tidak boleh diabaikan karena pengaruh yang terjadi cukup besar. Curah hujan juga berpengaruh terhadap kualitas tanah. Dalam mendesain fondasi, seorang insinyur perlu memperhatikan curah hujan optimal yang akan terjadi. Curah hujan yang tinggi berpengaruh pada karakteristik tanah 
dan muka air tanah. Semakin jenuh tanah dengan air dan muka air yang tinggi, maka karakteristik tanah menjadi lebih lunak. Selain memperhatikan tanah lunak dan curah hujan yang menjadi permasalahan dalam suatu proyek, topografi tanah dari suatu proyek juga menentukan kekuatan struktur suatu bangunan. Pembangunan dengan tujuan estetik di tepi lereng sangat tidak direkomendasikan. Penambahan beban pada tepi lereng dapat menurunkan faktor keamanan lereng dan menciptakan permasalahan slope stability.

Diansumsikan penyebab kegagalan rumah tinggal 2 lantai tersebut adalah karena pembangunan rumah tinggal di tepi lereng dengan lereng yang mempunyai tanah lunak. Penambahan beban di tepi lereng memberikan masalah pada slope stability yang mengurangi faktor keamanan suatu lereng. Pada desain fondasi juga diansumsikan curah hujan yang tinggi tidak diperhitungkan sehingga naiknya muka air tanah yang membuat tanah turun. Diduga besaran tahanan friksi negatif (negative skin friction) yang terjadi pada fondasi tidak diperhitungkan dan membuat fondasi tiang yang digunakan rusak. Permodelan dapat dilihat pada Gambar 1 dan Gambar 2:

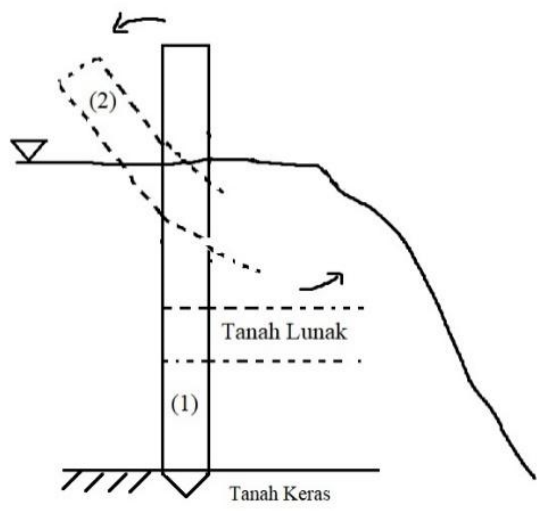

Gambar 1. (1) kondisi tiang mula-mula; (2) kondisi tiang yang patah akibat kesalahan desain fondasi

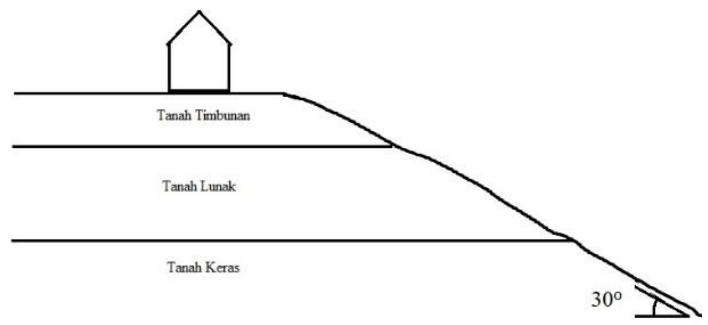

Gambar 2. Lokasi bangunan rumah tinggal 2 lantai pada lereng

\section{Tanah Lunak}

Tanah lunak memiliki daya dukung tanah yang kecil, pemampatan yang besar dan waktu konsolidasi yang lama (Das, 1998). Pada kondisi tanah dasar berupa tanah lempung yang sangat lunak dengan kemampuan daya dukung yang relatif terbatas, sering kali dijumpai permasalahan berupa kelongsoran pada tanah dasar pada saat pengaplikasian prabeban, sehingga harus melakukan proses penimbunan secara bertahap sesuai dengan kemampuan daya dukung tanah dan sering kali membutuhkan waktu yang lama. (Andryan Suhendra, 2011)

Tanah lempung kohesif diklasifikasikan sebgai tanah lunak apabila mempunyai daya dukung lebih kecil dari 0,5 $\mathrm{kg} / \mathrm{cm} 2$ dan nilai standard penetration test lebih kecil dari 4 ( $N$-value $<4)$. Berdasarkan uji lapangan, tanah lunak secara fisik dapat diremas dengan mudah oleh jari-jari tangan. (Terzaghi, 1967) Sifat umum tanah lunak adalah memiliki kadar air $80-100 \%$, batas cair $80-110 \%$, batas plastis 30-45\%, saat dites sieve analysis, maka butiran yang lolos oleh saringan no 200 akan lebih besar dari 90\% serta memiliki kuat geser 20-40 kN/m2. (Toha, 1989) 


\section{METODE PENELITIAN}

Dalam penelitian ini dilakukan beberapa tahapan sebagai berikut:

1. Tahapan pertama, mengumpulkan data-data yang digunakan untuk permodelan analisis kegagalan bangunan rumah tinggal 2 lantai seperti data tanah, data laboratorium, data visual dan data curah hujan.

2. Tahapan kedua, mengumpulkan studi literatur, teori-teori yang digunakan untuk melakukan desain fondasi, pengaruh negative skin friction, dan kestabilan lereng melalui buku-buku, jurnal dan tutorial.

3. Tahapan ketiga, korelasi data tanah yang ada dan menentukan parameter-parameter yang dibutuhkan dalam perhitungan.

4. Tahapan keempat, melakukan analisis perhitungan daya dukung tanah, pengaruh negative skin friction tiang pancang pada tanah lunak, dan menghitung besar faktor keamanan lereng sesuai dengan permodelan yang direncanakan.

5. Tahapan kelima, Penjabaran hasil perhitungan sesuai dengan permodelan yang diinginkan, desain lereng kemudian ditarik kesimpulan mengenai penyebab kegagalan model bangunan rumah tinggal 2 lantai akibat tanah lunak dan korelasinya terhadap curah hujan yang tinggi, kemudian menarik kesimpulan mengenai nilai kestabilan lereng akibat penambahan beban bangunan di tepi lereng yang cukup curam sesuai dengan permodelan yang direncanakan.

\section{HASIL DAN PEMBAHASAN}

Data tanah yang digunakan disesuaikan dengan model kegagalan bangunan rumah tinggal 2 lantai yang terjadi. Data tanah merupakan hasil intepretasi data tanah melalui pendekatan dari kasus nyata hasil pengamatan tak langsung di tempat kejadian. Data tanah dapat dilihat pada Tabel 2:

Tabel 2. Summary data tanah

\begin{tabular}{|c|c|c|c|c|c|c|c|}
\hline $\begin{array}{c}\text { Kedalaman } \\
(\mathrm{m})\end{array}$ & N-SPT & Konsistensi & $\begin{array}{c}\gamma_{\text {sat }} \\
\left(\text { ton } / \mathrm{m}^{3}\right)\end{array}$ & $\gamma_{\text {dry }}\left(\mathrm{ton} / \mathrm{m}^{3}\right)$ & $\mathrm{GS}$ & $\mathrm{e}$ & $\mathrm{Cu}\left(\mathrm{kN} / \mathrm{m}^{2}\right)$ \\
\hline $0-12$ & 2 & SOFT & 1,24 & 0,79 & 2,52 & 2,46 & 15 \\
\hline $12-18$ & 8 & MEDIUM STIFF & 1,18 & 0,86 & 2,56 & 2,21 & 46.8 \\
\hline $18-22$ & 25 & VERY STIFF & 1,2 & 1,17 & 2,63 & 1,24 & 150 \\
\hline $22-26$ & 11 & STIFF & 1,34 & 0,9 & 2,57 & 2,05 & 260 \\
\hline $26-30$ & 17 & STIFF & 1,11 & 1,06 & 2,62 & 1,46 & 264 \\
\hline $30-35$ & 44 & VERY STIFF & 1,48 & 1,21 & 2,63 & 1,6 & \\
\hline
\end{tabular}


Denah bangunan, letak fondasi, balok dan kolom yang digunakan pada permodelan ini dapat dilihat pada Gambar 5, Gambar 6, Gambar 7 dan Gambar 8:

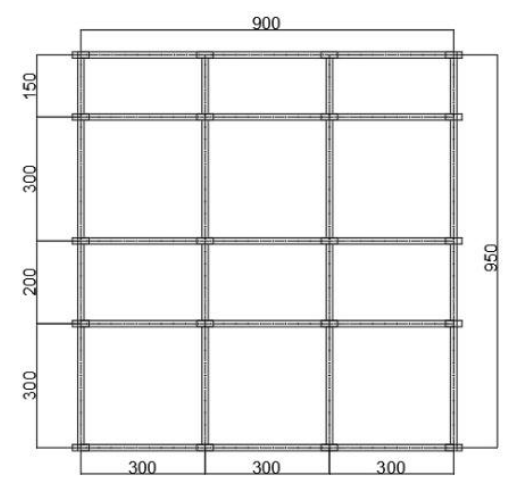

Gambar 5. Denah bangunan

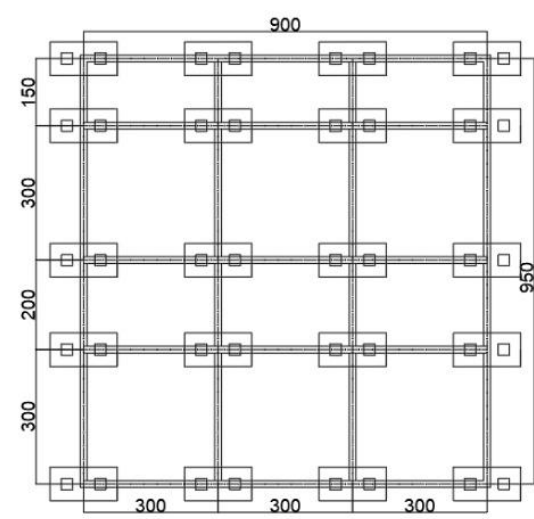

Gambar 6. Denah fondasi

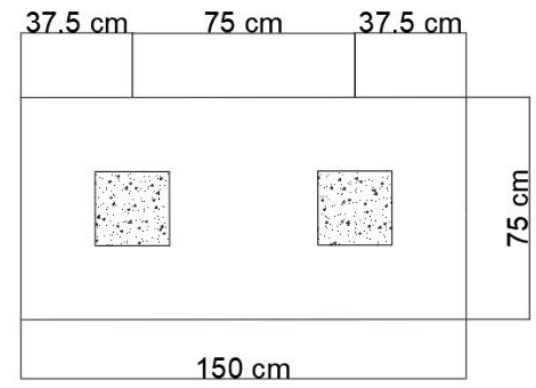

Gambar 7. Dimensi pile cap 


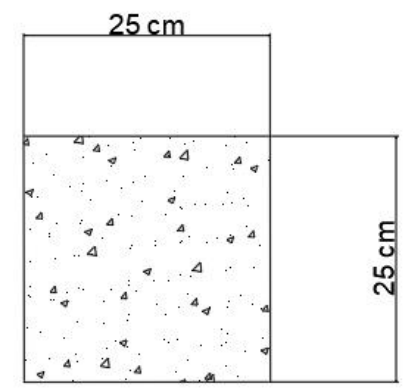

Gambar 8. Dimensi tiang pancang (bujur sangkar)

Untuk menghitung beban bangunan, dihitung menggunakan program aplikasi MIDAS GEN 2020. Berikut adalah hasil perhitungan (output) yang dihitung menggunakan program MIDAS yang dapat dilihat pada Tabel 3:

Tabel 3. Hasil perhitungan beban bangunan menggunakan program MIDAS GEN

\begin{tabular}{|c|c|c|c|c|c|c|}
\hline Nomor Kolom & FX (KN) & FY(KN) & FZ(KN) & MX(KNm) & MY(KNm) & MZ(KNm) \\
\hline 21 & 3,86 & $-0,27$ & 66,20 & 1,51 & 6,55 & 0,47 \\
\hline 22 & $-0,51$ & 2,70 & 64,31 & $-4,20$ & 1,50 & 0,52 \\
\hline 23 & 3,43 & $-2,46$ & 93,47 & 4,11 & 5,05 & 0,29 \\
\hline 24 & 0,09 & 0,92 & 74,51 & $-2,11$ & 1,18 & 0,33 \\
\hline 25 & 4,15 & $-1,18$ & 90,21 & 2,59 & 5,95 & $-0,03$ \\
\hline 26 & 0,92 & 2,12 & 71,30 & $-3,53$ & 2,22 & $-0,12$ \\
\hline 27 & 4,74 & $-2,34$ & 64,06 & 3,94 & 6,45 & 2,51 \\
\hline 28 & 5,78 & 1,10 & 83,92 & $-2,34$ & 9,09 & 2,86 \\
\hline 29 & $-15,09$ & $-1,77$ & 45,20 & 3,26 & $-31,83$ & 3,37 \\
\hline 30 & $-21,23$ & 1,50 & 47,87 & $-2,80$ & $-40,46$ & 4,11 \\
\hline 31 & $-19,05$ & $-0,65$ & 75,61 & 1,21 & $-36,67$ & 2,66 \\
\hline 32 & 5,40 & $-1,25$ & $114 ., 80$ & 1,92 & 7,41 & 2,12 \\
\hline 33 & 0,19 & 0,25 & 102,47 & 0,15 & 1,37 & 0,20 \\
\hline 34 & $-0,54$ & $-1,65$ & 105,53 & 2,39 & 0,47 & 0,36 \\
\hline 35 & 1,79 & 0,95 & 99,67 & $-0,68$ & 4,17 & 0,55 \\
\hline 36 & $-20,01$ & 0,01 & 73,80 & $-0,19$ & $-38,30$ & 2,43 \\
\hline 37 & 3,01 & $-0,08$ & 132,72 & $-0,09$ & 5,07 & 2,73 \\
\hline 38 & 1,83 & 0,91 & 94,60 & $-1,26$ & 3,27 & 0,16 \\
\hline 39 & 1,19 & $-0,50$ & 99,73 & 0,41 & 2,45 & 0,40 \\
\hline 40 & 2,12 & 1,69 & 100,74 & $-2,18$ & 4,54 & 0,59 \\
\hline
\end{tabular}

Perhitungan daya dukung tiang terdiri dari perhitungan daya dukung ujung tiang dan daya dukung selimut tiang. Perhitungan dilakukan secara manual dengan metode Mayerhoff (1956) menggunakan data N-SPT.

Pengaruh ujung tiang diansumsikan:

Atas : 8D (2m) -> elevasi $18 \mathrm{~m}$

Bawah : 4D (1m) -> elevasi 21m

Menghitung nilai Np rata-rata: 
$\mathrm{N}-\mathrm{SPT}$ di ujung tiang $(\mathrm{Np})=\frac{N-S P T 8 D+N-S P T \text { lokasi ujung tiang }+N-S P T 4 D}{3}$

$$
\begin{aligned}
& =\frac{8+25+25}{3} \\
& =19,33
\end{aligned}
$$

Menggunakan rumus Mayerhoff:

$$
\begin{aligned}
\mathrm{Qp}_{\text {tiang }}= & 4 \times \mathrm{Ap}_{\text {tiang }} \times \mathrm{Np} \\
\mathrm{Qp}_{\text {tiang }} & =4 \times 0,67 \mathrm{ft}^{2} \times 19,33 \\
& =52,03 \text { ton }
\end{aligned}
$$

Tiang pancang yang digunakan adalah tiang pancang beton (concrete pile) bertulang pejal, maka memiliki besar perpindahan besar.

$$
\begin{aligned}
\mathrm{QS}_{\text {tiang }} & =\frac{(\text { AStiang } x \underline{N})}{50} \\
& =\frac{215 x 5,73}{50} \\
& =24,66 \mathrm{ton} \\
\mathrm{Qu} & =\mathrm{Qp}+\mathrm{Qs} \\
& =52,03 \text { ton }+24,66 \text { ton } \\
& =76,88 \text { ton }
\end{aligned}
$$

Menghitung besar efisensi kelompok tiang:

$$
\begin{aligned}
\text { Eg } & =1-\frac{18,43}{90}\left[\frac{(2-1) 1+(1-1) 2}{1.2}\right] \\
& =0,898
\end{aligned}
$$

Menghitung Daya Dukung Kelompok Tiang:

$$
\begin{aligned}
\text { Qtk } & =\text { Eg x n x Qijin } \\
& =0,898 \times 2 \times 30,67 \text { ton } \\
& =55,06 \text { ton }
\end{aligned}
$$

Perhitungan Negative Skin Friction menggunakan metode Terzaghi-Peck Untuk menghitung besar negative skin friction, kita terlebih dahulu harus menentukan titik netral.

Menghitung titk netral:

$$
\begin{aligned}
\mathrm{D} & =0,75 \times \mathrm{H} \\
& =0,75 \times 20 \mathrm{~m} \\
& =15 \mathrm{~m}
\end{aligned}
$$

Menghitung negative skin friction :

Sesuai gambar desain fondasi pada gambar 4.3 maka digunakan L: 1,5 m; B: 0,75 m; H: 3 m.

$$
\begin{aligned}
\text { Qneg } & =\frac{1}{n}\left[2 \mathrm{D}+(\mathrm{L}+\mathrm{B}) \mathrm{C}_{\mathrm{u}}+\mathrm{BLH} \gamma\right. \\
& =\frac{1}{2}[2 \times 15+(1,5+0,75) 15+0,75 \times 1,5 \times 3 \times 12,16 \\
& =506,25 \mathrm{KN}+41,04 \mathrm{KN} \\
& =54,73 \mathrm{ton}
\end{aligned}
$$


JMTS: Jurnal Mitra Teknik Sipil

Vol. 4, No. 3, Agustus 2021: hlm 623-632

Menghitung resultan gaya:

$\mathrm{P}=13,27$ ton

$\mathrm{Qu}=76,88$ ton

Qneg =54,73 ton

Qakhir $=$ Qu-Qneg

$=76,88$ ton $-54,73$ ton

$=22,15$ ton

Pada hasil perhitungan ini, didapat daya dukung akhir tiang tunggal adalah 22,15 ton. Sesuai hasil perhitungan, Tiang dapat menahan beban aksial yang terjadi sebagai beban struktur yang sebesar 13,27 ton, Namun karena posisi rumah yang berada di tepi lereng diduga beban lateral yang muncul dan memukul tiang diabaikan pada saat mendesain tiang. Inilah yang menyebabkan kegagalan bangunan rumah tinggal 2 lantai tersebut.

Perhitungan Faktor Keamanan Lereng dihitung secara metode komputasi menggunakan program GeoStudio. Perhitungan dilakukan menggunakan metode Bishop. Permodelan lereng dilakukan dengan hasil analisis pengamatan secara tidak langsung pada lokasi gagalnya bangunan rumah tinggal 2 lantai tersebut. Permodelan lereng dapat dilihat pada Gambar 9 dan Gambar 10 :

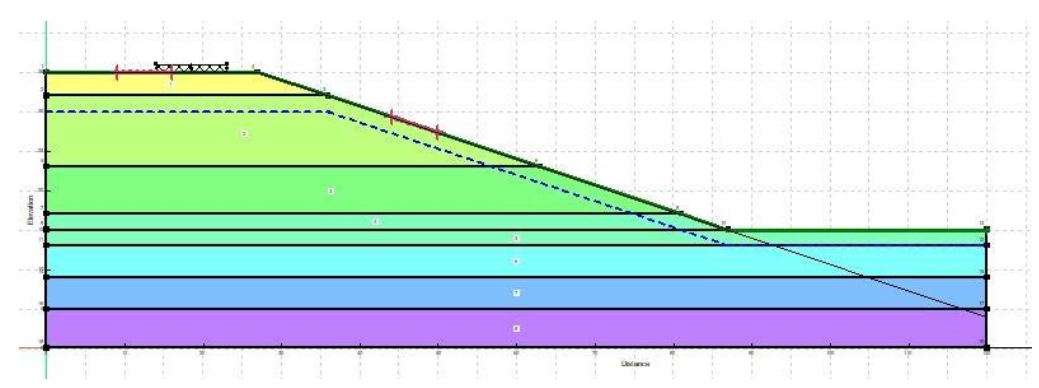

Gambar 9. Permodelan lereng akibat curah hujan yang tinggi

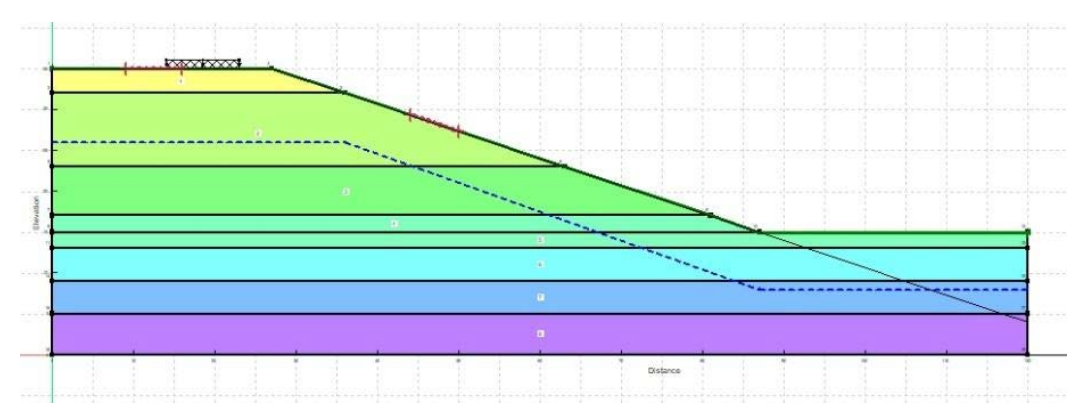

Gambar 10. Permodelan lereng pada muka air tanah normal 


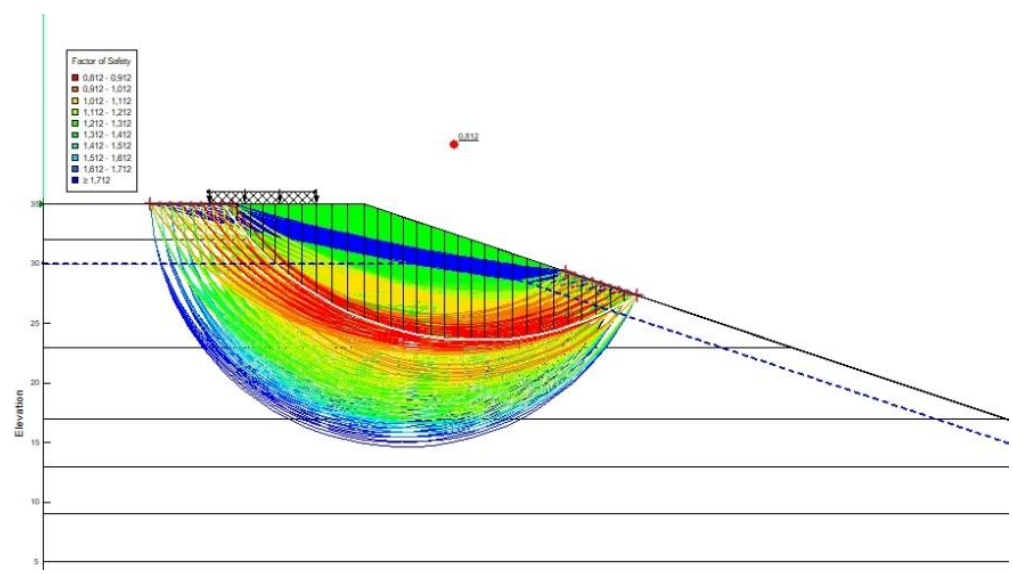

Gambar 11. Kontur Permukaan Longsor akibat curah hujan yang tinggi

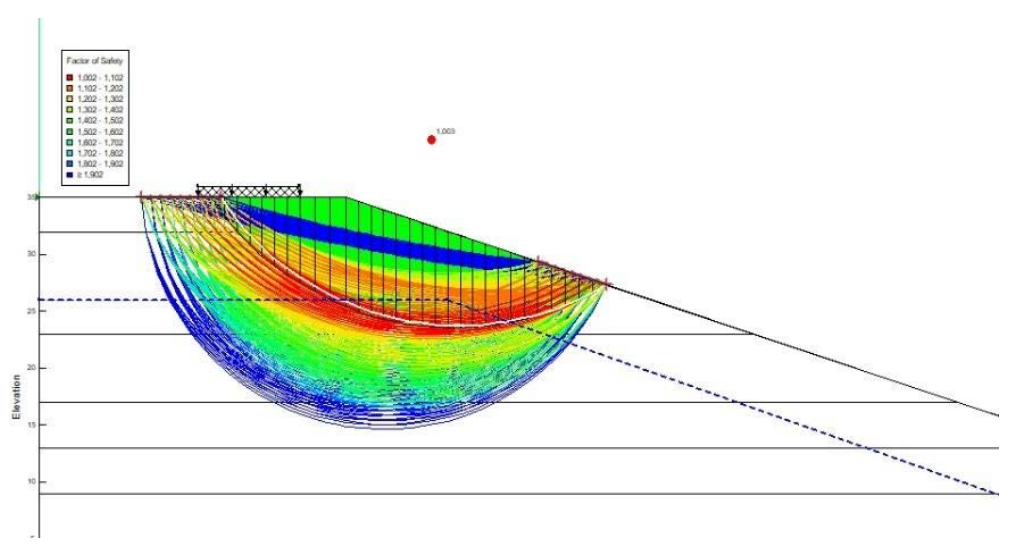

Gambar 12. Kontur permukaan longsor pada muka tanah air normal

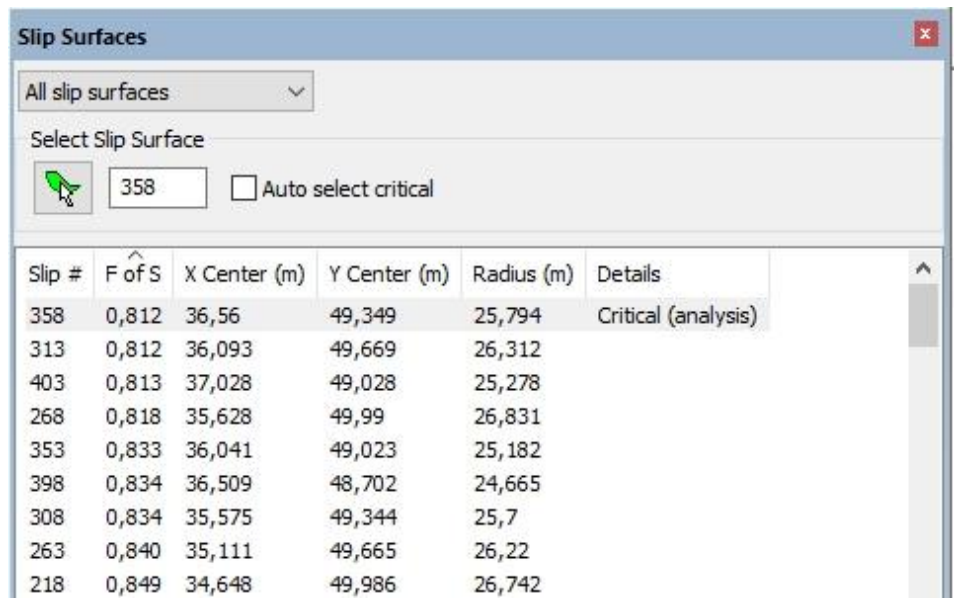

Gambar 13. Hasil perhitungan faktor keamanan dengan metode Bishop 


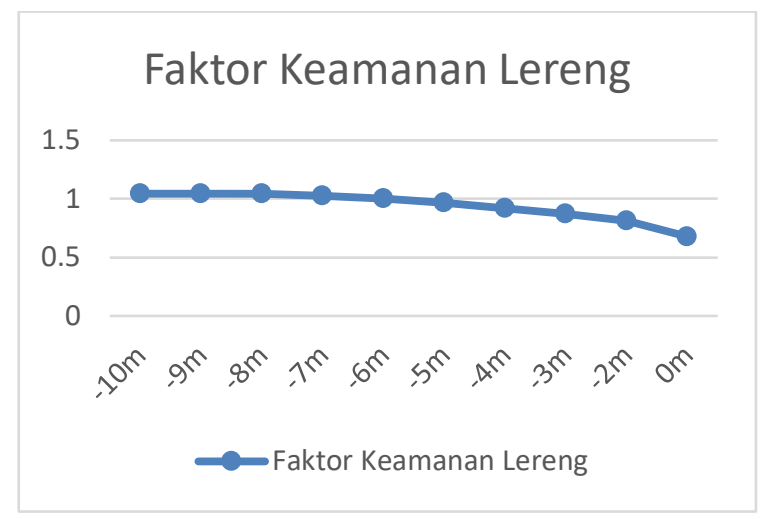

Gambar 14. Grafik Faktor keamanan lereng dengan MAT berbeda

Perhitungan secara komputasi menggunakan program aplikasi GeoStudio 2018 dilakukan dengan metode perhitungan menurut Bishop. Dimodelkan posisi bangunan rumah tinggal 2 lantai tserbut berada di tepi lereng, Tepatnya sejauh 4 meter dari tepi lereng. Kermiringan lereng dimodelkan sebesar $30^{\circ}$. Karena curah hujan yang tinggi dan terjadi secara berturut-turut yang terjadi pada bulan tersebut, air muka tanah naik sampai setinggi 2 m dibawah tanah aslinya.

Hasil perhitungan faktor keamanan diambil yang terkecil. Dari hasil perhitungan faktor keamanan menggunakan metode Bishop dapat dilihat pada Gambar 13 dan Gambar 14. Pada Gambar 13, perhitungan dengan metode Bishop pada program GeoStudio didapat angka faktor keamanan 0,812 pada akibat curah hujan yang tinggi dan 1,003 pada keadaan tanah normal. Menurut Bowles (1984) lereng yang mempunyai faktor keamanan dibawah 1,07 adalah lereng dengan kondisi tidak stabil. Seringkali dan bisa saja lereng tersebut mengalami longsor. Maka tidak disarankan untuk melakukan pembangunan ataupun aktivitas lainnya yang mengganggu kestabilan lereng. Pada Gambar 11 dan Gambar 12 dapat dilihat kontur permukaan longsor pada muka air tanah normal dan pada kondisi tanah jenuh air.

Perhitungan negative skin friction berpengaruh juga terhadap kestabilan lereng. Pada mula-mula lereng berada dalam kondisi stabil, namun akibat penambahan beban dan negative skin friction dalam jangka waktu yang lama selama pembangunan konstruksi, Kondisi lereng tersebut menjadi kritis dan labil. Hasil perhitungan faktor keamanan lereng dilakukan dengan tinggi muka air tanah yang bervariasi dari -10m sampai kondisi tanah jenuh pada elevasi 0 . Hasil perhitungan faktor keamanan lereng dapat dilihat pada Gambar $14 \mathrm{Hal}$ ini menandakan bahwa semakin tinggi curah hujan dan naiknya muka air tanah ke permukaan, maka faktor keamanan lereng semakin menurun.

\section{KESIMPULAN DAN SARAN}

\section{Kesimpulan}

Dari hasil analisis permodelan ini didapatkan beberapa kesimpulan yaitu:

1. Daya dukung tiang menggunakan metode Mayerhoff didapatkan sebesar 76,88 ton dan besar negative skin friction yang didapat dengan permodelan ini adalah 54,73 ton.

2. Faktor keamanan lereng yang dihitung dengan metode Bishop didapatkan faktor keamanan lereng sebesar 0,812 dengan muka air tanah naik akibat curah hujan yang tinggi dan 1,003 pada saat keadaan muka air tanah normal, Yang menyatakan bahwa lereng tersebut berada dalam kondisi labil dan bisa saja terjadi longsor.

3. Penyebab kegagalan bangunan rumah tinggal 2 lantai tersebut tidak hanya diakibatkan oleh curah hujan yang tinggi, melainkan disebabkan juga oleh munculnya fenomena negative skin friction yang terjadi pada tiang tersebut.

4. Negative skin friction yang terjadi pada fondasi dalam dengan tanah lunak tidak boleh diabaikan karena pengaruhnya terhadap beban yang dipikul oleh tiang semakin meningkat.

5. Dalam mendesain suatu fondasi, perlu diperhitungkan curah hujan optimal yang dapat berpengaruh terhadap kualitas tanah proyek. 


\section{Saran}

Dari hasil perhitungan daya dukung tiang, dapat dilakukan metode perhitungan lainnya agar hasil dapat dibandingkan. Selain itu, diharapkan perhitungan faktor keamanan lereng dapat dihitung dengan metode lain dan program lain untuk melakukan verifikasi agar hasil perhitungan yang didapat lebih akurat.

\section{DAFTAR PUSTAKA}

Andryan Suhendra, M. I. (2011). Studi Aplikasi Vacuum Preloading sbagai Metode Alternatif Percepatan Proses Konsolidasi pada Tanah Lempung Lunak Jenuh Air: Trial GVS pada Perumahan Pantai Indah Kapuk, Jakarta. ComTech Vol.2.

Das, Braja. M. 1998. Principles of Foundation Engineering Forth Edition. PWS Publishing. California.

Rajapakse, Ruwan Abey. Geotechnical Engineering Calculations and Rules of Thumb. New York: Joe Hayton, 2016.

Shamser Prakash, Hari D. Sharma. Pile Foundations in Engineering Practice. Canada: A-Wiley Interscience Publication, 1990.

Terzaghi, K. A. (1967). Soil Mechanics in Engineering Practice. USA: John Wiley and Sons, Inc, USA.2nd Edition. Toha, F. X. (1989). Karakteristik Konsolidasi Lempung Lunak Banjarmasin. National Symposium on Soft Soil and Landslides. HATTI. Bandung.

Zakaria, Z. (2009). Analisis Kestabilan Lereng Tanah. Bandung : Laboratorium Geologi Teknik Universitas Padjadjaran. 